\title{
ASPECTOS REPRODUTIVOS E POTENCIAL DE EMERGÊNCIA DE PLÂNTULAS DE Cryptostegia madagascariensis Bojer ex Decne
}

\author{
REPRODUCTIVE ASPECTS AND POTENTIAL OF SEEDLING EMERGENCY OF \\ Cryptostegia madagascariensis Bojer ex Decne
}

\author{
Maria Lúcia Maurício da Silva ${ }^{1}$ Leonaldo Alves de Andrade ${ }^{2}$ Edlânia Maria de Souza ${ }^{3}$ \\ Patrícia Cândido da Cruz Silva ${ }^{4}$
}

\begin{abstract}
RESUMO
Invasão biológica é o processo no qual um organismo exótico, quando adaptado, passa a competir com as espécies nativas causando graves impactos. A espécie Cryptostegia madagascariensis Bojer ex. Decne, introduzida no Brasil com fins paisagísticos, tem se revelado uma espécie invasora bastante agressiva no bioma caatinga formando maciços autorregenerantes principalmente em áreas degradadas e às margens dos cursos de água e lagoas temporárias. Objetivou-se com este estudo avaliar aspectos reprodutivos (através da caracterização biométrica) e o potencial de emergência de plântulas de Cryptostegia madagascariensis. Para a caracterização biométrica, frutos (com coloração verde) e sementes (com coloração branca) tiveram suas dimensões mensuradas, aferindo-se ainda o número de sementes por fruto e a massa fresca de frutos e sementes. Para a avaliação da influência da posição e profundidade de semeadura na emergência de plântulas, as sementes foram semeadas em areia esterilizada com o hilo para baixo, para cima e para o lado, nas profundidades de 0,$5 ; 1,0 ; 1,5 ; 2,0 ; 2,5$ e $3,0 \mathrm{~cm}$. A elevada produção de sementes muito leves por fruto e, por conseguinte, de sementes por indivíduo potencializa o caráter invasor de Cryptostegia madagascariensis. A emergência e o vigor de plântulas de Cryptostegia madagascariensis são reduzidos pelo aumento da profundidade.
\end{abstract}

Palavras-chave: Caatinga; invasão biológica; Apocynaceae; espécie invasora.

\begin{abstract}
Biological invasion is the process in which an exotic organism, when adapted, shall compete with native species causing serious impacts. The species Cryptostegia madagascariensis introduced in Brazil with landscaping purposes has proved to be a very aggressive invasive species in Caatinga, forming self-regenerating masses, especially in degraded areas and on the banks of watercourses and temporary ponds. The objective of this study was to evaluate the reproductive aspects (through biometric characterization) and the potential emergence of Cryptostegia madagascariensis seedlings. To characterize biometric fruits (green colored) and seeds (white colored) had their dimensions measured by assessing whether even the number of seeds per fruit, and fresh weight of fruits and seeds. To evaluate the influence of the position and depth of sowing on seedling emergence, seeds were placed in sterile sand substrate with the hilum down, up and

1 Engenheira Agrônoma, Doutoranda do Programa de Pós-graduação em Agronomia, Centro de Ciências Agrárias, Universidade Federal da Paraíba, Rodovia PB-079, CEP 58397-000, Areia (PB), Brasil. luciagronomia@hotmail.com

2 Engenheiro Agrônomo, Dr., Professor do Departamento de Fitotecnia e Ciências Ambientais, Universidade Federal da Paraíba, Rodovia PB-079, CEP 58397-000, Areia (PB), Brasil. professorleonaldo@gmail.com

3 Engenheira Agrônoma, Mestranda do Programa de Pós-graduação em Agronomia, Centro de Ciências Agrárias, Universidade Federal da Paraíba, Rodovia PB-079, CEP 58397-000, Areia (PB), Brasil. edlania.maria@hotmail.com

4 Engenheira Agrônoma, Doutoranda do Programa de Pós-Graduação em Agronomia (Produção Vegetal), Universidade Estadual Paulista, Via de Acesso Prof. Paulo Donato Castellane s/n, CEP 14884-900, Jaboticabal (SP), Brasil. patriciacandidocs@gmail.com
\end{abstract}


sideways at depths of $0.5 ; 1.0 ; 1.5 ; 2.0 ; 2.5$ and $3.0 \mathrm{~cm}$. The high production of very light seeds per fruit, and therefore, the seeds per individual, associated with the absence of natural enemies potentiates the intruder character of Cryptostegia madagascariensis. The emergence and vigor of Cryptostegia madagascariensis seedlings are reduced by the increase in depth.

Keywords: Caatinga; biological invasion; Apocynaceae; invasive species.

\section{INTRODUÇÃO}

A invasão biológica é caracterizada pela introdução de um organismo exótico em um ambiente distinto de sua ocorrência natural e ao se adaptar passa a dominar as espécies nativas, sendo por isso considerada uma das maiores causas de perda de biodiversidade do planeta (ZENNI; ZILLER, 2011). Ainda de acordo com os mesmos autores, no Brasil constata-se degradação ambiental causada pela invasão biológica em todos os biomas e em diferentes intensidades. No Nordeste, a caatinga é um bioma no qual se tem observado grande ocorrência de espécies invasoras, a exemplo de Calotropis procera (Aiton) W.T. Aiton (FABRICANTE; OLIVEIRA; SIQUEIRA FILHO, 2013), Nicotiana glauca Graham (FABRICANTE et al., 2015), Parkinsonia aculeata L. (AGRA et al., 2015), Sesbania virgata (Cav.) Pers. (SOUZA et al., 2011) e Prosopis juliflora (Sw.) DC. (ANDRADE; FABRICANTE; OLIVEIRA, 2010), as quais já foram identificadas como espécies invasoras, verificando-se sérios prejuízos à biodiversidade autóctone.

Atualmente, outra espécie exótica que tem se destacado como invasora no referido bioma é Cryptostegia madagascariensis Bojer ex Decne. A espécie exótica, da família Apocynaceae, endêmica da Ilha de Madagascar (África) é um arbusto trepador, heliófilo, que ocorre desde o nível do mar até regiões mais secas como as savanas, dominando notadamente zonas perturbadas, áreas de matas ciliares e/ ou sazonalmente alagadas (ENDRESS; BRUYNS, 2000; KLACKENBERG, 2001).

No Brasil, Cryptostegia madagascariensis foi provavelmente introduzida com fins ornamentais, particularmente por sua popularidade como planta decorativa devido à sua floração lilás. Entretanto, pelo fato da espécie produzir grande quantidade de sementes viáveis, por apresentar dispersão anemocórica e alto percentual de germinação, fugiu do controle, e assim compete com as espécies nativas provocando a eliminação das mesmas, principalmente devido à competição estabelecida em função da formação de maciços monoespecíficos (STARR; STARR, K; LOOPE, 2003). Apesar do porte arbustivo, atingindo de 2 a $3 \mathrm{~m}$ de altura, Cryptostegia madagascariensis desenvolve ramos trepadores podendo alcançar alturas consideráveis, usando como suporte, por exemplo, outras plantas; e, ao se desenvolver sobre a copa dos indivíduos, impede a passagem de luz, causando a morte destes por sombreamento excessivo; essa característica também limita ou até anula o desenvolvimento da regeneração natural (VIEIRA et al., 2004).

Espécies vegetais que se tornam invasoras geralmente apresentam características ou atributos que as tornam melhores competidoras, tais como: rápido crescimento, grande produção de sementes pequenas e de fácil dispersão, presença de substâncias tóxicas e alta taxa de germinação de sementes, que conferem a estes organismos vantagens competitivas em relação às espécies nativas, exercendo assim dominância nos novos espaços ocupados (VIGILATO; ZAMPAR, 2011). Outro fator determinante para o estabelecimento das espécies no novo ambiente é a ausência de inimigos naturais (BLOSSEY, 2011). O uso excessivo dos recursos naturais que fragiliza os ambientes e diminui efetivamente a diversidade natural do ecossistema invadido também é um dos principais fatores que contribuem para o estabelecimento de espécies exóticas (ZANCHETTA; DINIZ, 2006). Segundo Mack et al. (2000), as ações antrópicas são as principais responsáveis pelo surgimento de condições favoráveis ao estabelecimento de espécies invasoras.

Em estudos ecológicos, a caracterização biométrica de frutos e sementes pode ser feita com as mais diversificadas finalidades. A classificação das sementes por tamanho ou por peso é uma estratégia geralmente adotada para uniformizar a emergência das plântulas e para obtenção de mudas de tamanho semelhante ou de maior vigor (CARVALHO; NAKAGAWA, 2012). Além disso, estudos sobre biometria podem avaliar a variabilidade genética dentro de uma mesma população, e as relações entre esta variabilidade e os fatores ambientais (GONÇALVES et al., 2013). Algumas características morfológicas, como o tamanho dos frutos e das sementes, estão relacionadas principalmente com as estratégias reprodutivas das plantas; sendo assim, o estudo dos aspectos biométricos destes torna-se indispensável para o melhor entendimento dos aspectos 
ecológicos envolvendo a germinação e o estabelecimento das espécies vegetais (MATOS et al., 2014).

A profundidade de semeadura é específica para cada espécie e, quando adequada, propicia germinação e emergência de plântulas uniformes, porém, profundidades excessivas de semeaduras podem impedir que a plântula ainda frágil emerja à superfície do solo; e, se reduzidas, predispõem as sementes à variação ambiental, podendo originar plântulas pequenas e fracas (TILLMANN et al., 1994). O entendimento de como a germinação e emergência de espécies invasoras responde a fatores ambientais, notadamente no que se refere ao conhecimento sobre a profundidade na qual a plântula é capaz de emergir, é de grande importância para compreender a capacidade adaptativa, o potencial invasor e, principalmente, para contribuir na adoção de práticas de manejo, como o emprego de métodos mecânicos associados ou não a métodos químicos (GIACONTTI et al., 2011).

Considerando a escassez de trabalhos científicos referentes às espécies invasoras, no bioma caatinga, principalmente em relação aos aspectos biométricos e morfológicos de sementes e plântulas, e aspectos germinativos de sementes, este estudo teve como objetivo avaliar aspectos reprodutivos e o potencial de emergência de plântulas de Cryptostegia madagascariensis.

\section{MATERIAL E MÉTODOS}

O estudo foi realizado no Laboratório de Ecologia Vegetal (LEV) pertencente ao Centro de Ciências Agrárias (CCA) da Universidade Federal da Paraíba (UFPB), em Areia - PB. As sementes de Cryptostegia madagascariensis foram oriundas de frutos coletados, manualmente, sobre a copa de matrizes na Fazenda Triunfo (Latitude 444'18,2436” S; Longitude 3845’08,3952”' O; Altitude 110 m), município de Ibaretama - CE, quando os mesmos ainda apresentavam coloração verde uniforme (não estavam na fase de liberação espontânea das sementes). Em seguida foram acondicionados em sacos plásticos e levados ao LEV, onde foram determinadas as características biométricas de frutos e sementes, e realizados testes para avaliar a emergência e vigor das plântulas em diferentes posições e profundidades de semeadura.

Em uma amostra homogênea de 200 frutos (folículos), provenientes de 50 matrizes, foram determinadas as seguintes características biométricas: comprimento - medido com o auxílio de um paquímetro digital $(0,01 \mathrm{~mm})$, sendo considerada a porção compreendida entre a base e o ápice; largura e espessura - obtidas a partir da medida da parte intermediária, sendo a largura a maior distância perpendicular ao eixo do comprimento e a espessura a medida perpendicular à largura; número de sementes. fruto $^{-1}$ contabilizando-se o número total de sementes de cada fruto amostrado; peso fresco de cada fruto - obtido em balança de precisão $(0,0001 \mathrm{~g})$; e número de sementes danificadas por insetos - considerando-se a semente que apresentasse orifício visível a olho nu, indicando a presença de larva ou indivíduo adulto. Para a caracterização das sementes, utilizou-se uma amostra homogênea de 200 sementes, extraídas dos 200 frutos previamente mensurados, determinando-se: comprimento, largura e espessura - seguindo-se o mesmo procedimento utilizado para frutos; e o peso de mil sementes, obtido conforme Brasil (2009).

Para avaliar a emergência e vigor das plântulas de Cryptostegia madagascariensis, quatro repetições de 25 sementes foram semeadas em bandejas de polietileno $(45 \times 30 \times 7 \mathrm{~cm}$ de comprimento, largura e espessura, respectivamente) contendo como substrato areia lavada e esterilizada em autoclave a $120^{\circ} \mathrm{C}$ durante 120 minutos. Os tratamentos consistiram em diferentes posições: sementes com o hilo voltado para baixo (HB), para o lado (HL) e para cima (HC) no substrato, nas profundidades de 0,$5 ; 1,0 ; 1,5 ; 2,0 ; 2,5$ e $3,0 \mathrm{~cm}$. O teste foi conduzido em casa de vegetação, sem controle de temperatura e umidade, com reposição de água, de abastecimento urbano, diariamente até se verificar o início da drenagem natural.

As variáveis analisadas foram: emergência - as contagens foram feitas diariamente, do sétimo ao trigésimo dia após a instalação do teste, computando-se as plântulas que apresentavam parte do hipocótilo acima da superfície do substrato, seguindo-se preferencialmente o mesmo horário; primeira contagem conduzida conjuntamente com o teste de emergência, no qual se contabilizaram as plântulas emergidas no sétimo dia após a semeadura, sendo os resultados expressos em porcentagem; índice de velocidade de emergência - a velocidade de emergência foi determinada mediante contagem diária do número de plântulas emersas durante 30 dias e o índice determinado de acordo com Maguire (1962); comprimento e massa seca de plântulas - a raiz primária e a parte aérea das plântulas normais de cada repetição foram medidas individualmente, com auxílio de régua graduada, aos 30 dias após semeadura, sendo os resultados 
expressos em cm.plântulas ${ }^{-1}$. Após medidas, raízes e parte aérea foram colocadas em sacos de papel-kraft e acondicionadas em estufa de secagem a $65^{\circ} \mathrm{C}$ por 48 horas, e em seguida pesadas em balança analítica com precisão de $0,001 \mathrm{~g}$.

Os dados biométricos foram submetidos à estatística descritiva por meio de parâmetros estimados, organizados em classes de frequência e plotados em histograma de frequência. Para o teste de emergência, utilizou-se delineamento inteiramente casualizado com os tratamentos distribuídos em esquema fatorial 3 x 6 (posições e profundidades de semeadura) com quatro repetições de 25 sementes. Os dados obtidos foram submetidos à análise de variância e as médias comparadas pelo teste de Scott-Knott $(\mathrm{p} \leq 0,05)$. Para os efeitos quantitativos foi realizada análise de regressão polinomial, utilizando-se o programa estatístico SISVAR 5.1 (FERREIRA, 2007).

\section{RESULTADOS E DISCUSSÃO}

Na Tabela 1 estão apresentados os dados biométricos de frutos e sementes de Cryptostegia madagascariensis, observando-se que os mesmos apresentaram pouca variação em suas dimensões. Em relação aos frutos foram encontrados valores médios de: $6,86 \pm 0,75 \mathrm{~cm}$ para o comprimento; $2,49 \pm 0,28$ $\mathrm{cm}$ para a largura; $1,87 \pm 0,21 \mathrm{~cm}$ para a espessura; e 12,17 $\pm 3,76 \mathrm{~g}$ de peso fresco. O número médio de sementes por fruto amostrado foi de $105,30 \pm 18,12$. As sementes apresentaram em média $0,71 \pm 0,05 \mathrm{~cm}$ de comprimento, $0,29 \pm 0,04 \mathrm{~cm}$ de largura e $0,10 \pm 0,02 \mathrm{~cm}$ de espessura. $O$ peso de 1.000 (mil) sementes foi de $13,31 \mathrm{~g}$, o que corresponde a $0,01 \mathrm{~g}$. semente ${ }^{-1}$.

Diante dos resultados obtidos, pode-se afirmar que as sementes de Cryptostegia madagascariensis são pequenas e bastante leves, mesmo quando ainda não estão secas. O tamanho e o peso das sementes para algumas espécies podem ser considerados um indicativo de sua qualidade fisiológica (SANTOS NETO et al., 2009), têm influência no estabelecimento e dispersão das espécies, com modos alternativos de dispersão (DEMINICIS et al., 2009) e, também, estão relacionados à competição, predação e distribuição espacial (BRAGA et al., 2007).

Constatou-se maior frequência de frutos variando nas classes de $6,03-7,06 \mathrm{~cm}$ para o comprimento; 2,43 - 2,86 cm para a largura; e 1,70 - 2,13 cm para a espessura, correspondendo a 45,5; 45 e $67 \%$ da amostra total, respectivamente (Figura 1A-C). Em relação ao peso observa-se maior frequência dos frutos amostrados (44\%) pesando entre 7,50 - 12,50 g, com a maioria (67\%) destes apresentando de 97-131 sementes por fruto (Figura 1D-E).

Realizando a biometria de frutos e sementes de Calotropis procera (Apocynaceae), espécie também exótica e invasora de ambientes ruderais, e pertencente à mesma família de Cryptostegia madagascariensis,

TABELA 1:Valores (máximo, mínimo, médio, desvio padrão e coeficiente de variação $(\mathrm{CV})$ ) referentes à biometria de frutos e sementes de Cryptostegia madagascariensis Bojer ex Decne.

TABLE 1:Values (maximum, minimum, average, standard deviation and coefficient of variation (CV)) for the biometrics of fruits and seeds Cryptostegia madagascariensis Bojer ex Decne.

\begin{tabular}{lcccccc}
\hline & Determinações & Máximo & Mínimo & Médio & Desvio padrão & CV (\%) \\
\hline \multirow{4}{*}{ Fruto } & Comprimento $(\mathrm{cm})$ & 8,60 & 4,50 & 6,86 & 0,75 & 10,97 \\
& Largura $(\mathrm{cm})$ & 3,50 & 1,80 & 2,49 & 0,28 & 11,37 \\
& Espessura $(\mathrm{cm})$ & 3,20 & 1,49 & 1,87 & 0,21 & 11,24 \\
& Peso $(\mathrm{g})$ & 25,00 & 5,00 & 12,17 & 3,76 & 28,43 \\
& $\mathrm{~N}^{\mathrm{o}}$ sementes fruto $^{-1}$ & 148,0 & 12,0 & 105,30 & 18,12 & 17,21 \\
\hline \multirow{4}{*}{ Semente } & Comprimento $(\mathrm{cm})$ & 0,84 & 0,60 & 0,71 & 0,05 & 7,88 \\
& Largura $(\mathrm{cm})$ & 0,60 & 0,20 & 0,29 & 0,04 & 14,38 \\
& Espessura $(\mathrm{cm})$ & 0,20 & 0,09 & 0,10 & 0,02 & 22,55 \\
& Peso de mil sementes $(\mathrm{g})$ & - & - & 13,31 & - & - \\
\hline
\end{tabular}



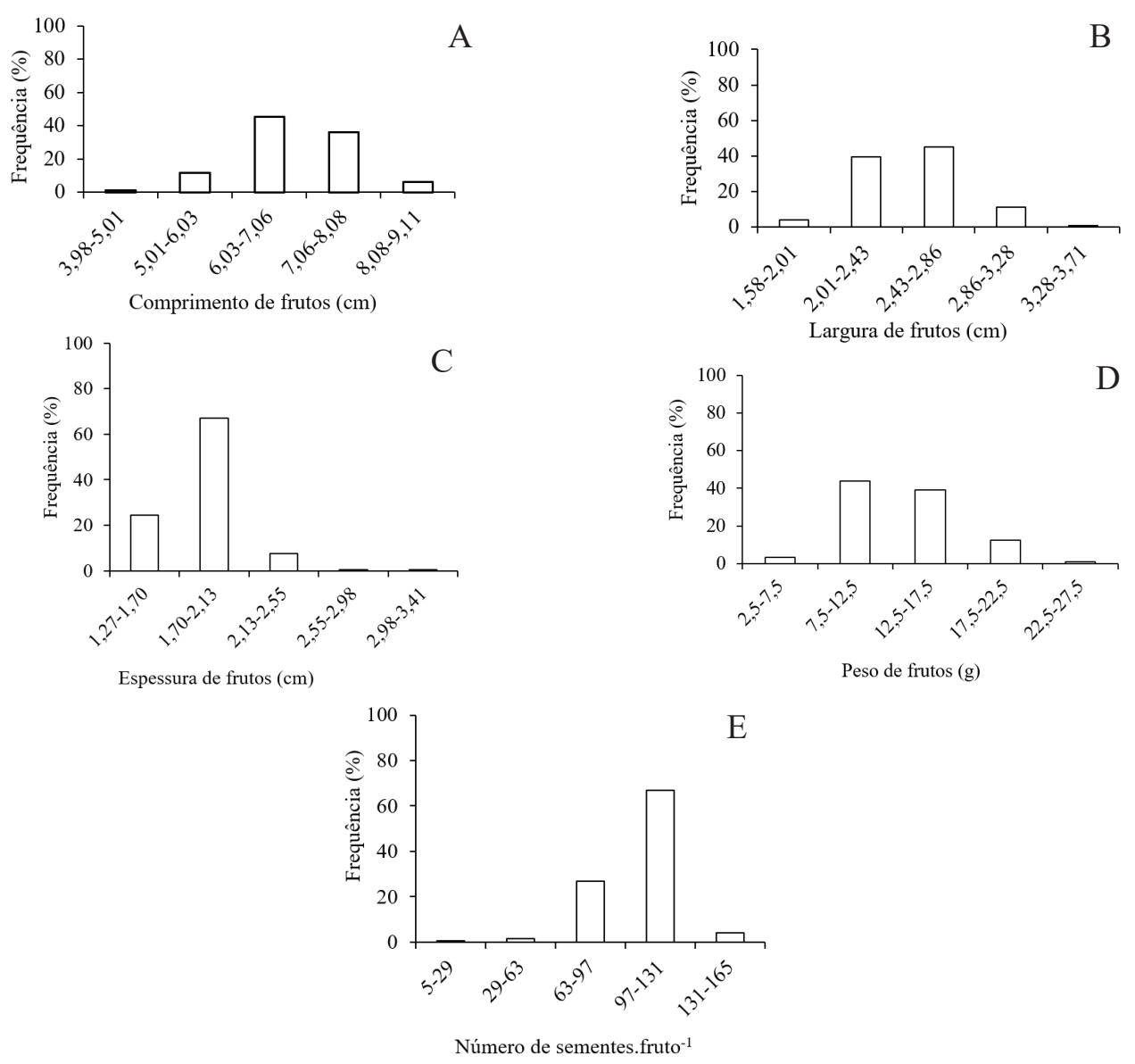

FIGURA 1: Frequência relativa do comprimento (A), largura (B), espessura (C) e peso (D) de frutos, e número de sementes por fruto (E) de Cryptostegia madagascariensis Bojer ex Decne.

FIGURE 1: Relative length frequency (A), width (B), thickness (C) and weight (D) of fruits and number of seeds per fruit (E) of Cryptostegia madagascariensis Bojer ex Decne.

Oliveira-Bento et al. (2013) constataram maior número de frutos com valores de comprimento variando entre 9,0 e $12,0 \mathrm{~cm}(57,1 \%)$, largura entre 4,0 e $7,0 \mathrm{~cm}(43,8 \%)$ e espessura entre 4,0 e $7,0 \mathrm{~cm}(57,1 \%)$, a maioria destes (52,5\%) pesando de 20,1 - 30,0 g, com média de 387,17 $\pm 73,12$ sementes por fruto. Em Cryptostegia grandiflora $\mathrm{R}$. Br., os folículos são ainda maiores, medindo, na maturidade, cerca de 12,5 $\mathrm{cm}$ de comprimento e produzindo mais sementes, em média 668 por fruto, segundo Tomley (1995). Por outro lado, em estudos com espécies nativas, foram encontrados valores bem inferiores aos obtidos para espécies exóticas: em Mauritia flexuosa L.f., Matos et al. (2014) obtiveram médias de 4,495 $\pm 0,569 \mathrm{~cm}$ para o comprimento, 3,649 $\pm 0,539 \mathrm{~cm}$ para a largura, 3,595 $\pm 0,467 \mathrm{~cm}$ para a espessura e $19,60 \pm 5,93$ g para o peso de frutos. Avaliando frutos e sementes de diferentes espécies de Hymenaea, Cunha-Silva, Rodrigues e Miranda (2012) verificaram média de 11,6 cm de comprimento, 4,9 cm de largura e 3,9 cm de espessura, com produção de 1 a 11 sementes por fruto de Hymenaea courbaril var. stilbocarpa, e para frutos de Hymenaea martiana, os mesmos autores obtiveram, em média, 10,2 cm de comprimento, 5,0 $\mathrm{cm}$ de largura e $3,7 \mathrm{~cm}$ de espessura, com produção de 1 a 9 sementes por frutos. O grande potencial de disseminação de Cryptostegia madagascariensis, em função do grande número de sementes produzidas, e consequentemente de estabelecimento em diferentes áreas, é uma característica que, provavelmente deixa a invasora em vantagem competitiva em relação às espécies nativas, as quais geralmente produzem pequena quantidade de sementes quando comparadas às espécies invasoras acima mencionadas.

Na Figura 2A-C observa-se predominância de sementes variando nas classes de 0,69-0,75 cm de comprimento (66,5\%); 0,25 - 0,35 cm largura (85,5\%) e 0,07 - 0,10 cm de espessura (85\%). Dados semelhantes foram observados por Oliveira-Bento et al. (2013) para sementes de Calotropis procera, 

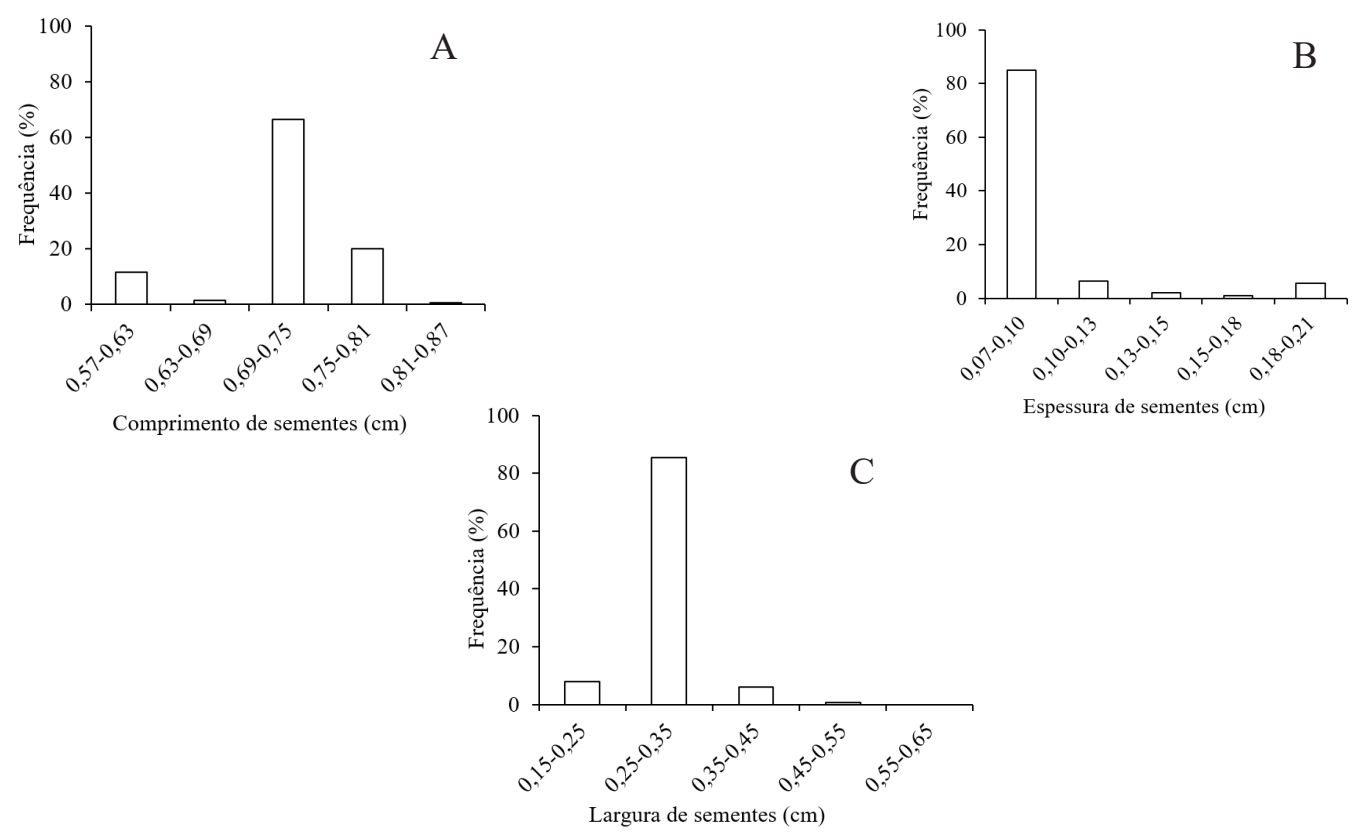

FIGURA2: Frequência relativa do comprimento (A), largura (B) e espessura (C) de sementes de Cryptostegia madagascariensis Bojer ex Decne.

FIGURE 2: Frequency relative length (A), width (B) and thickness (C) of seeds of Cryptostegia madagascariensis Bojer ex Decne.

as quais apresentaram comprimento variando de 0,5 a $0,8 \mathrm{~cm}$ e largura de 0,4 a $0,6 \mathrm{~cm}$, com espessura constante de $0,1 \mathrm{~cm}$, e peso médio de semente estimado de $0,008 \mathrm{~g} . s e m e n t e s^{-1}$, sendo o peso médio de mil sementes igual a $8,54 \mathrm{~g}$.

As sementes amostradas não apresentaram sintomas de ataque por insetos, sugerindo que a ausência de inimigos naturais aumenta consideravelmente a quantidade de sementes viáveis, resultando em uma planta com alta resistência ecológica. Silva e Cavalcante (2009) estudando o gênero Cryptostegia no estado do Ceará, em diferentes condições ambientais, também confirmaram a ausência de inimigos naturais. Por outro lado, Cunha-Silva, Rodrigues e Miranda (2012) analisando sementes de duas espécies nativas do gênero Hymenaea verificaram que 18 e 48,9\% dos frutos de Hymenaea courbaril var. stilbocarpa e Hymenaea martiana, respectivamente, apresentavam $100 \%$ de suas sementes danificadas por insetos, o que contribui para o controle natural das populações nativas, fato não verificado em espécies invasoras.

$\mathrm{Na}$ Tabela 2, referente ao resumo da análise de variância dos dados para avaliação da emergência e vigor de plântulas de Cryptostegia madagascariensis, observou-se que a interação entre posição e profundidade de semeadura não foi significativa para a porcentagem e índice de velocidade de emergência, e massa seca da parte aérea das plântulas, evidenciando que os fatores estudados atuam de forma independente sobre estas variáveis. O coeficiente de variação para a primeira contagem de emergência de plântulas foi bastante alto $(62,32 \%)$, indicando variabilidade dos dados em relação à média, provavelmente em função da diferença de profundidade de semeadura entre os tratamentos, resultando em desuniformidade da emergência.

Os resultados obtidos para a invasora Cryptostegia madagascariensis concordam com os encontrados por Freire et al. (2014) e Martins et al. (2012) para as espécies Bauhinia divaricata L. e Schizolobium parahyba (Vell.) S.F. Blake, respectivamente, os quais verificaram que a posição da semente no substrato não influenciou a porcentagem e a velocidade de emergência de plântulas, bem como não ocorreu interação entre os fatores estudados.

$\mathrm{Na}$ Figura 3 observa-se que as profundidades de semeadura de 0,5 e 1,0 $\mathrm{cm}$ proporcionaram às plântulas melhor resposta para a porcentagem de emergência, sendo responsável por 79,33 e 83,67\%, respectivamente. À medida que houve aumento na profundidade de semeadura observou-se redução no porcentual de plântulas emersas, verificando-se uma redução de $41 \%$ na profundidade de $3,0 \mathrm{~cm}$. 
TABELA 2: Resumo da análise de variância da emergência (E), índice de velocidade de emergência (IVE), primeira contagem (PC), comprimento de raízes (CR) e de parte aérea (CPA) e massa seca de raízes (MSR) e de parte aérea (MSPA) de plântulas de Cryptostegia madagascariensis Bojer ex Decne.

TABLE 2: Summary of analysis of variance of emergency (E), emergence rate index (IVE), first count (PC), root length (CR) and shoot (CPA) and root dry matter (RDM) and part (MSPA) seedling Cryptostegia madagascariensis Bojer ex Decne.

\begin{tabular}{lcccccccc}
\hline \multirow{2}{*}{ Fator de variação } & \multirow{2}{*}{ GL } & \multicolumn{7}{c}{ Quadrados Médios } \\
\cline { 3 - 9 } & & $\mathrm{E}$ & IVE & PC & CR & CPA & MSR & MSPA \\
\hline Posição (Pos) & $213,63^{\text {ns }}$ & $0,08^{\text {ns }}$ & $0,48^{\text {ns }}$ & $0,93^{\text {ns }}$ & $0,75^{*}$ & $0,38^{*}$ & $0,02^{\text {ns }}$ \\
Profundidade (Prof) & 6 & $10415,60^{*}$ & $9,68^{*}$ & $175,87^{*}$ & $72,59^{*}$ & $59,73^{*}$ & $0,32^{*}$ & $1,06^{*}$ \\
Pos x Prof & 11 & $81,64^{\text {ns }}$ & $0,16^{\text {ns }}$ & $13,30^{*}$ & $5,80^{*}$ & $1,33^{*}$ & $0,18^{*}$ & $0,01^{\text {ns }}$ \\
Resíduo & 64 & 98,62 & 0,10 & 4,72 & 0,91 & 0,19 & 0,004 & 0,01 \\
CV (\%) & & 17,07 & 21,40 & 62,32 & 17,81 & 8,83 & 36,52 & 24,65 \\
\hline
\end{tabular}

Em que: ns= não significativo; *significativo a 5\% de probabilidade pelo teste de Scott-Knott.

Avaliando a viabilidade de sementes de Cryptostegia madagascariensis, provenientes de frutos com pericarpo verde-amarelado, nas temperaturas constantes de 25 e $30^{\circ} \mathrm{C}$ e alternada de $20-30^{\circ} \mathrm{C}$, em três condições de luminosidade (luz ambiente, luz suplementar e sem luz), Vieira et al. (2004) obtiveram média de $93 \%$ de germinação. Grice (1996) obteve germinação acima de $80 \%$ ao avaliar a viabilidade de sementes de Cryptostegia grandiflora sob diferentes temperaturas. Entretanto, Alves et al. (2013), avaliando sementes da espécie nativa Talisia esculenta (A. St. Hil) Radlk, observaram que a semeadura com o hilo para cima ou na vertical em profundidades entre 2,5 e $3,0 \mathrm{~cm}$, promoveu maior emergência, indicando que o efeito da posição e profundidade de semeadura sobre a emergência e vigor de plântulas depende de cada espécie.

Segundo Silva (1992), em profundidades excessivas, especialmente nas espécies de sementes menores (a exemplo de Cryptostegia madagascariensis), ocorre impedimento ou retardamento da emergência da plântula por insuficiência de energia para tal processo. O conhecimento da espessura do solo na qual a plântula é capaz de emergir auxilia na junção de práticas de controle de espécies invasoras, como por exemplo: o emprego de métodos mecânicos associados ou não a métodos químicos (TOLEDO; KUVA; ALVES, 1993). Provavelmente, a capacidade de plântulas de Cryptostegia madagascariensis emergirem em menores profundidades seja mais um dos fatores que favorece a espécie no processo de invasão,

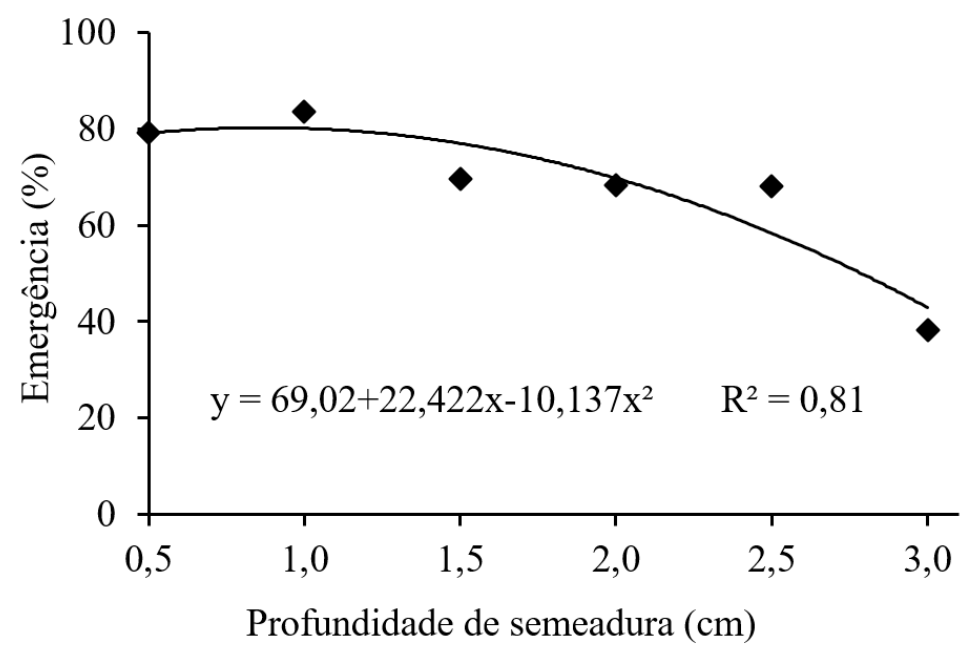

FIGURA 3: Emergência (\%) de plântulas de Cryptostegia madagascariensis Bojer ex Decne em função da profundidade de semeadura.

FIGURE 3: Emergence (\%) of seedlings of Cryptostegia madagascariensis Bojer ex Decne depending on the sowing depth. 
especialmente em áreas que apresentam solos compactados, o que dificulta a penetração espontânea das sementes, a exemplo da área onde se coletou as sementes utilizadas neste estudo.

Em relação à primeira contagem de emergência (Figura 4), é possível observar que, para todas as posições em que as sementes foram colocadas no substrato, houve redução do número de plântulas emersas à medida que a semeadura se tornou mais profunda. A maior porcentagem de emergência na primeira contagem foi obtida quando as sementes foram colocadas no substrato com o hilo para baixo na profundidade de $0,5 \mathrm{~cm}$, contudo, quando comparada às demais posições do hilo, a redução foi mais acentuada com o aumento da profundidade, obtendo-se valores nulos a partir de $2,5 \mathrm{~cm}$ de profundidade. Sementes colocadas no substrato com o hilo voltado para cima resultaram em menor percentual (30\%) de plântulas emersas aos $0,5 \mathrm{~cm}$ de profundidade, em relação às posições com o hilo voltado para baixo e para o lado.

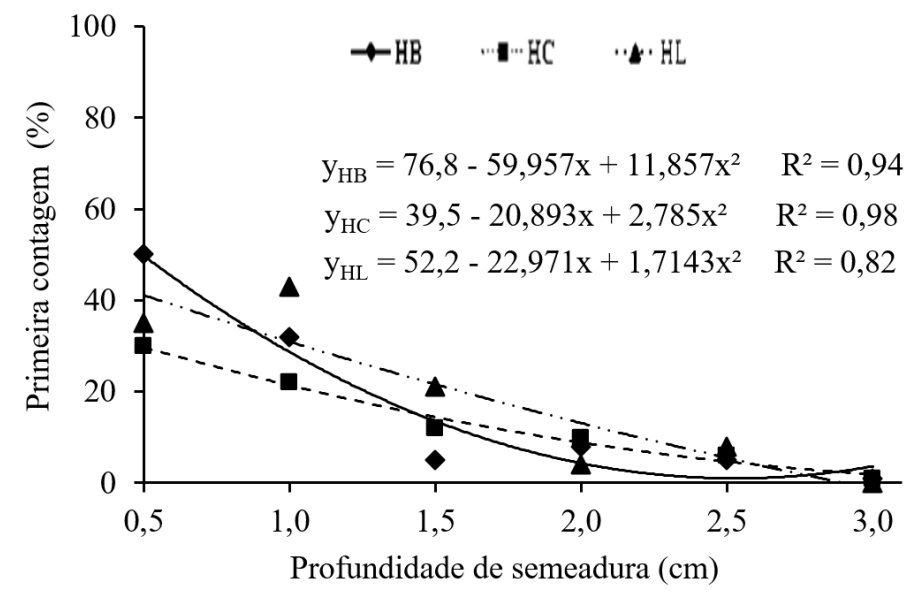

FIGURA 4: Primeira contagem (\%) de emergência de plântulas de Cryptostegia madagascariensis Bojer ex Decne em função de posições e profundidades de semeadura. Sendo: $\mathrm{HB}=$ hilo para baixo; $\mathrm{HC}=$ hilo para cima; $\mathrm{HL}=$ hilo para o lado.

FIGURE 4: First count (\%) of seedling emergence of Cryptostegia madagascariensis Bojer ex Decne related to positions and sowing depths. Where: $\mathrm{HB}=$ hilum downwards, $\mathrm{HC}=$ hilum upward, $\mathrm{HL}=$ hilum to the side.

Em um estudo com sementes de Bauhinia divaricata, Freire et al. (2014) também observaram redução da emergência à medida que a profundidade de semeadura aumentou, atingindo valores nulos na primeira contagem após $4 \mathrm{~cm}$ de profundidade, na posição de semeadura com o hilo para o lado. Os autores justificaram essa redução, nas maiores profundidades, pela maior dificuldade das plântulas em superarem o obstáculo em que se constitui o substrato. Alves et al. (2014) constataram que a maior porcentagem de emergência de plântulas de Platymiscium floribundum Vog. na primeira contagem foi alcançada quando a semente foi posicionada com o hilo para baixo nas profundidades de $0,1,2,3,4,5$ e $6 \mathrm{~cm}$.

Os resultados obtidos para o índice de velocidade de emergência de plântulas de Cryptostegia madagascariensis (Figura 5) foram semelhantes àqueles verificados para a porcentagem de emergência (Figura 3), uma vez que não houve interação significativa entre posição e profundidade de semeadura. Quando os fatores foram analisados isoladamente constatou-se que a velocidade de emergência foi reduzida à proporção que ocorreu aumento da profundidade de semeadura.

Estes resultados divergem dos obtidos para sementes de Platymiscium floribundum, nos quais Alves et al. (2014) verificaram que o índice de velocidade de emergência das plântulas foi reduzido significativamente, à medida que foi aumentando a profundidade, em todas as posições (hilo voltado para baixo, para cima e para o lado). Para Talisia esculenta, Alves et al. (2013) constataram que as posições das sementes com o hilo para cima e na vertical foram as mais adequadas porque proporcionaram uma emergência elevada e uniforme. De acordo com Cardoso et al. (2008), o IVE é reduzido com o aumento da profundidade porque associado a uma maior barreira física existe maior concentração de $\mathrm{CO}_{2}$, resultando em efeito fitotóxico afetando tanto a porcentagem quanto a velocidade de emergência das plântulas, além 


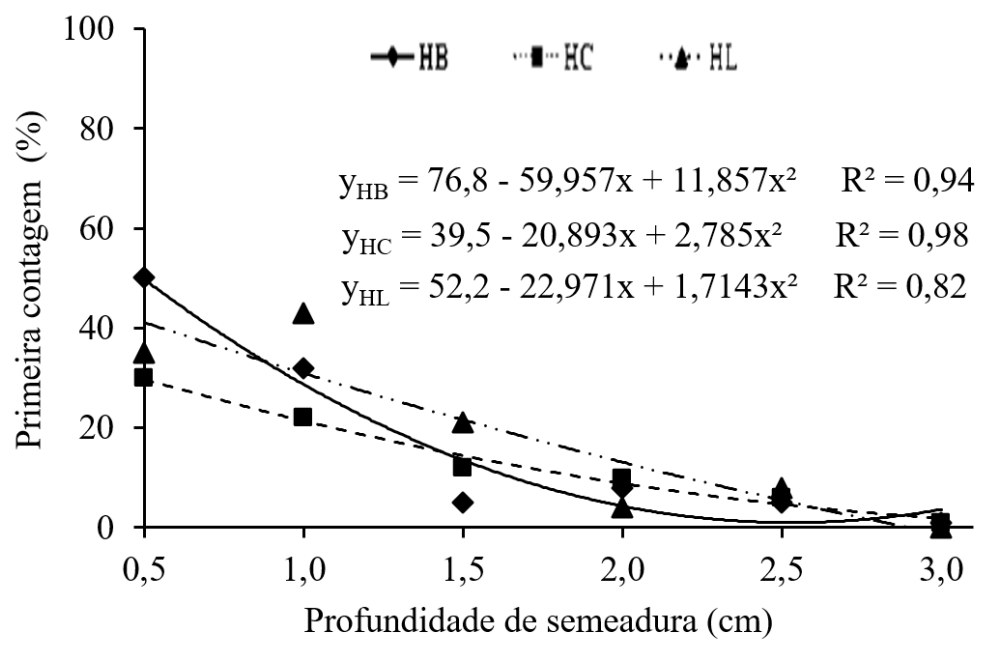

FIGURA 5: Índice de velocidade de emergência de plântulas de Cryptostegia madagascariensis Bojer ex Decne em função de profundidades de semeadura.

FIGURE 5: Speed of emergence index seedling of Cryptostegia madagascariensis Bojer ex Decne due to the sowing depths.

das flutuações das temperaturas diurnas e noturnas favorecerem as sementes que se encontram em menores profundidades.

Na Figura 6A, referente ao comprimento de raízes de plântulas de Cryptostegia madagascariensis, verificou-se que não houve ajuste aos modelos polinomiais testados para os tratamentos nos quais as sementes foram semeadas com o hilo para baixo e para o lado, obtendo-se médias de 6,39 e $6,31 \mathrm{~cm}$, respectivamente. As plântulas oriundas de sementes semeadas com o hilo voltado para cima sofreram redução no comprimento das raízes à medida que a semeadura tornou-se mais profunda. Quando o vigor das plântulas de Cryptostegia madagascariensis foi avaliado pelo comprimento da parte aérea (Figura 6B), verificou-se que apenas os dados referentes ao tratamento em que as sementes foram posicionadas com o hilo voltado para baixo na semeadura não se ajustaram aos modelos de regressão polinomiais, obtendo-se média de $5,77 \mathrm{~cm}$. As plântulas originadas de sementes colocadas no substrato com o hilo para cima e para o lado sofreram um acréscimo significativo no comprimento de parte aérea, a partir da profundidade de 2,0 $\mathrm{cm}$.

Semelhante aos resultados encontrados neste estudo para o comprimento de plântulas de Cryptostegia madagascariensis, Alves et al. (2014) também verificaram decréscimo linear no comprimento da raiz primária de plântulas de Platymiscium floribundum com o aumento da profundidade, para todas as posições. No entanto, quando as sementes foram semeadas com o hilo para o lado, na profundidade de $4 \mathrm{~cm}$, e para baixo a $5 \mathrm{~cm}$, originaram plântulas com raízes mais compridas, o que, segundo o autor, ocorreu devido a um gasto maior de energia durante a fase de emergência, prejudicando o desenvolvimento normal das plântulas oriundas dessas sementes. Freire et al. (2014) também verificaram aumento linear no comprimento da parte aérea de plântulas de Bauhinia divaricata à medida que a profundidade de semeadura aumentou para as posições da semente com o hilo para baixo e para cima.

As plântulas de Cryptostegia madagascariensis oriundas de sementes colocadas no substrato com o hilo voltado para baixo e para cima, nas profundidades de 1,0 e 1,5 cm, foram responsáveis pelos maiores conteúdos de massa seca de raízes (Figura 7A), enquanto o menor valor foi obtido de plântulas oriundas de sementes posicionadas com o hilo para o lado, independentemente da profundidade de semeadura. $\mathrm{Na}$ Figura 7B observa-se que os maiores conteúdos de massa seca de parte aérea foram obtidos de plântulas oriundas de sementes semeadas na profundidade de $1,0 \mathrm{~cm}$, independentemente da posição em que as sementes foram colocadas no substrato durante a semeadura. Em seguida, verifica-se redução significativa, à medida que houve aumento na profundidade de semeadura, para todas as posições em que a semente foi colocada no substrato. 

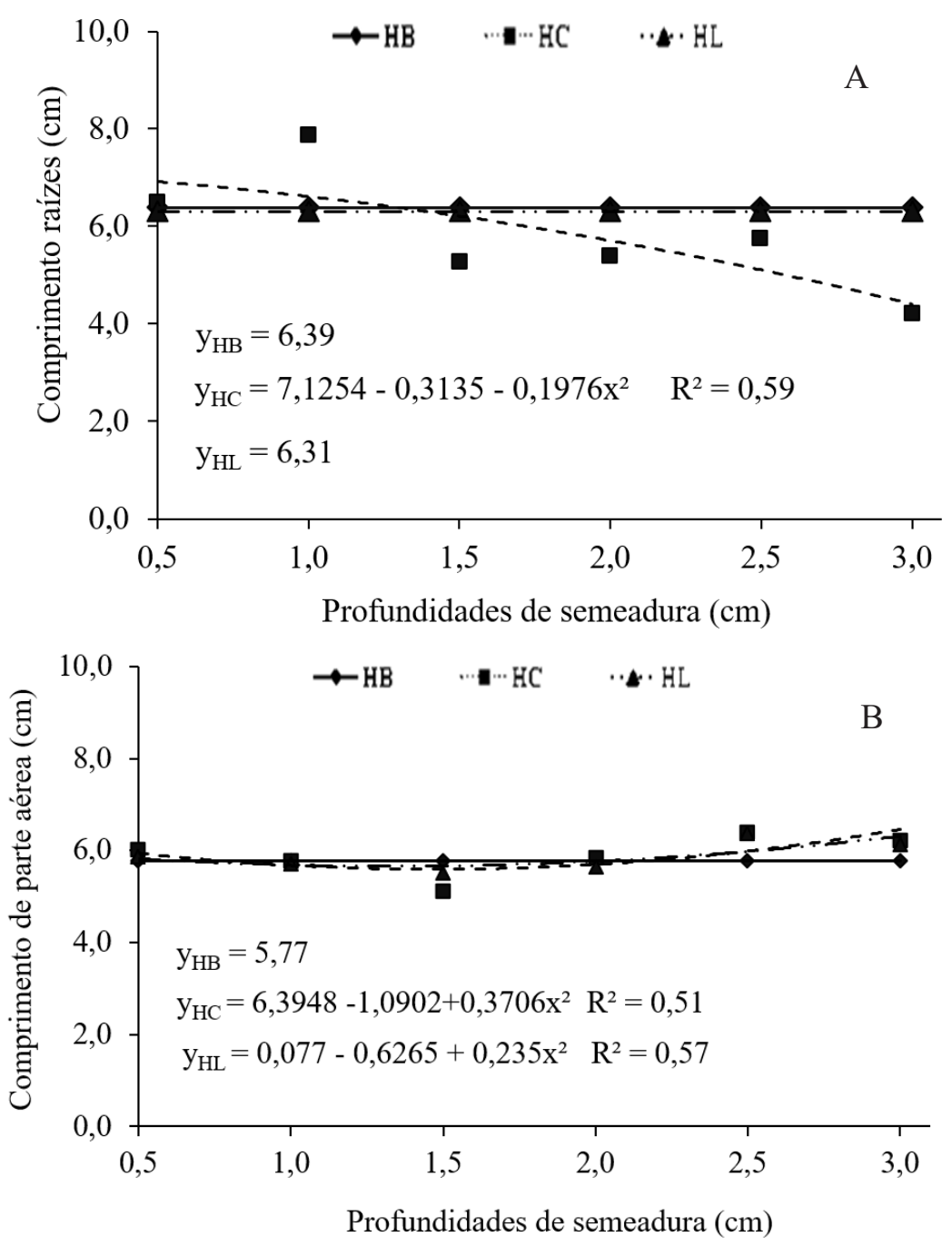

FIGURA 6: Comprimento de raízes (A) e de parte aérea (B) de plântulas de Cryptostegia madagascariensis Bojer ex Decne em função de posições e profundidades de semeadura. Sendo: $\mathrm{HB}=$ hilo para baixo; $\mathrm{HC}=$ hilo para cima; $\mathrm{HL}=$ hilo para o lado.

FIGURE 6: Root length (A) and shoots (B) seedling of Cryptostegia madagascariensis Bojer ex Decne related to positions and sowing depths. Where: $\mathrm{HB}=$ hilum downwards, $\mathrm{HC}=$ hilum upward, $\mathrm{HL}=$ hilum to the side.

Os resultados obtidos neste estudo, para as variáveis massa seca de raízes e de parte de plântulas de Cryptostegia madagascariensis, concordam com os resultados verificados por Rodrigues et al. (2016) para a massa seca de raízes de Acacia polyphylla DC., nos quais os autores verificaram redução linear quando as sementes foram posicionadas com o hilo voltado para cima ou foram dispostas horizontalmente. Laime et al. (2010) constataram que, para plântulas de Inga ingoides (Rich.) Willd., as sementes posicionadas com o hilo para o lado e para baixo resultaram em redução significativa da massa seca radicular à medida que aumentava a profundidade da semeadura.

Embora tenha ocorrido aumento do comprimento de parte aérea de plântulas de Cryptostegia madagascariensis com o aumento de profundidade, isto não se refletiu no teor de massa seca das mesmas, provavelmente porque à medida que a profundidade aumenta, as plântulas tendem a apresentar menor diâmetro do hipocótilo utilizando suas reservas prioritariamente para o crescimento vertical, resultando em menor valor de massa seca. 

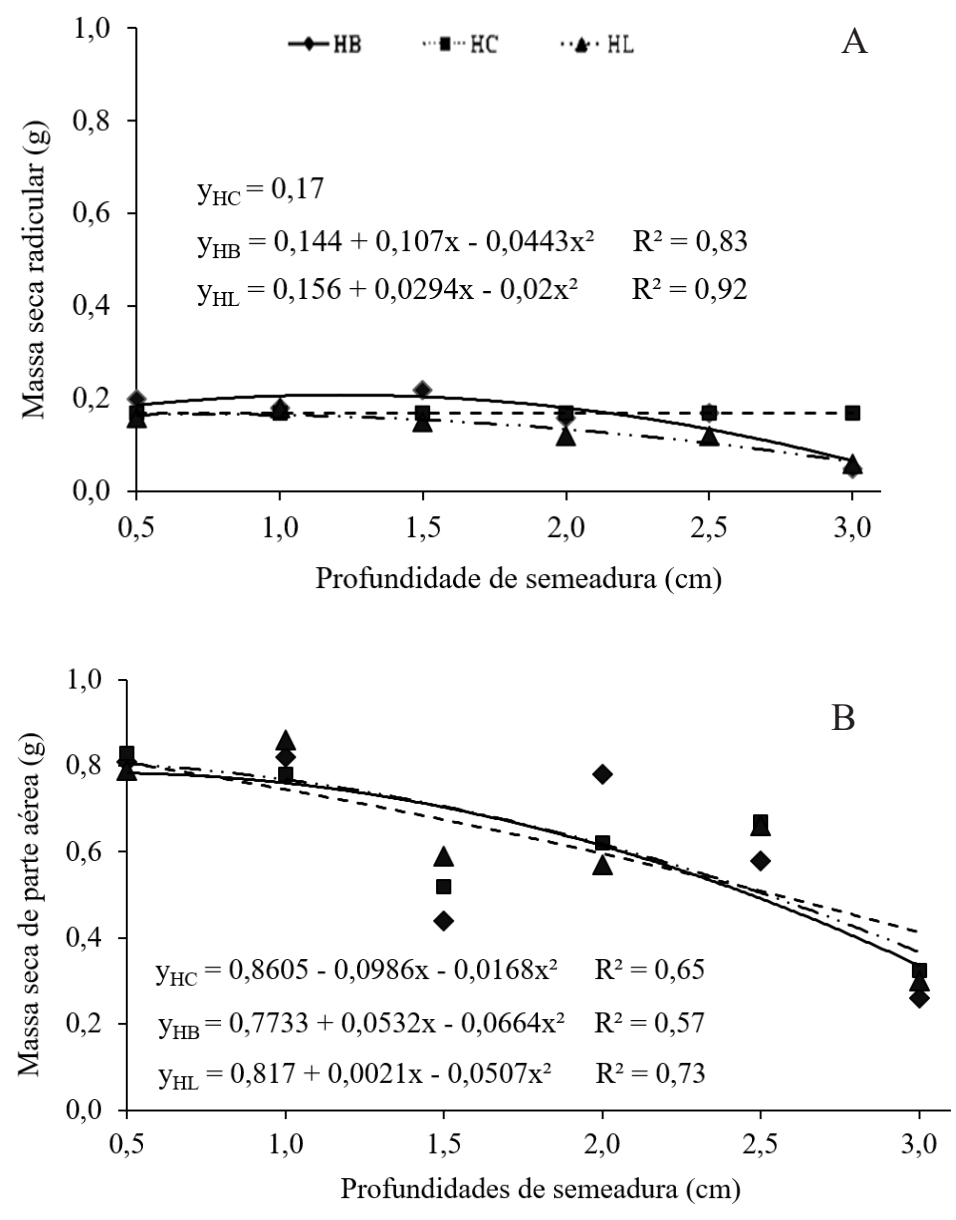

FIGURA 7: Massa seca de raízes (A) e de parte aérea (B) de plântulas de Cryptostegia madagascariensis Bojer ex Decne em função de posições e profundidades de semeadura. Sendo: $\mathrm{HB}=$ hilo para baixo; $\mathrm{HC}=$ hilo para cima; $\mathrm{HL}=$ hilo para o lado.

FIGURE 7: Root dry mass (A) and shoots (B) seedling Cryptostegia madagascariensis Bojer ex Decne function positions and sowing depths. Where: $\mathrm{HB}=$ hilum downwards, $\mathrm{HC}=$ hilum upward, $\mathrm{HL}=$ hilum to the side.

\section{CONCLUSÕES}

A elevada produção de sementes muito leves por fruto e, por conseguinte, de sementes por indivíduo, potencializa o caráter invasor de Cryptostegia madagascariensis.

A emergência e o vigor de plântulas de Cryptostegia madagascariensis são reduzidos pelo aumento da profundidade.

\section{AGRADECIMENTOS}

Ao Projeto Biomas e à Confederação da Agricultura e Pecuária do Brasil (CNA) em parceria com a Empresa Brasileira de Pesquisa Agropecuária (EMBRAPA), pelo suporte financeiro. Ao Sr. Wellington Ribeiro, proprietário da fazenda Triunfo, Ibaretama - CE, por viabilizar a realização desse trabalho. 


\section{REFERÊNCIAS}

AGRA, P. F. M. et al. Métodos para superação da dormência de sementes de Parkinsonia aculeata L. Semina: Ciências Agrárias, Londrina, v. 36, n. 3, p. 1191-1202, 2015.

ALVES, E. U. et al. Emergência e crescimento inicial de plântulas de Talisia esculenta (A. St. Hil) Radlk em função de profundidades e posições de semeadura. Bioscience Journal, Uberlândia, v. 29, n. 2 , p. 328-339, 2013.

ALVES, M. M. et al. Emergência e crescimento inicial de plântulas de Platymiscium floribundum Vog. em função de diferentes posições e profundidades de semeadura. Ciência Rural, Santa Maria, v. 44, n. 12, p. 2129-2135, 2014.

ANDRADE, L. A.; FABRICANTE, J. R.; OLIVEIRA, F. X. Impactos da invasão de Prosopis juliflora (Sw.) DC. (Fabaceae) sobre o estrato arbustivo-arbóreo em áreas de Caatinga no Estado da Paraíba, Brasil. Acta Scientiarum - Biological Sciences, Maringá, v. 32, n. 3, p. 249-255, 2010.

BLOSSEY, B. Enemy release hypothesis. In: SIMBERLOFF, D.; REJMANEK, M. Encyclopedia of biological invasions. Berkeley: University of California Press, 2011. p. 193-195.

BRAGA, L. F. et al. Caracterização morfométrica de sementes de castanha de sapucaia (Lecythis pisonis) Cambess - Lecythidaceae. Revista de Ciências Agro-Ambientais, Alta Floresta, v. 5, n. 1, p. 111-116, 2007.

BRASIL. Ministério da Agricultura, Pecuária e Abastecimento. Regras para análise de sementes. Brasília: Ministério da Agricultura, Pecuária e Abastecimento, 2009. 399 p.

CARDOSO, E.A. et al. Emergência de plântulas de Erythrina velutina em diferentes posições e profundidades de semeadura. Ciência Rural, Santa Maria, v. 38, n. 9, p. 2618-2621, 2008.

CARVALHO, N. M.; NAKAGAWA, J. Sementes: ciência, tecnologia e produção. 5. ed. Jaboticabal: FUNEP, 2012. 590 p.

CUNHA-SILVA, G. R.; RODRIGUES, C. M.; MIRANDA, S. C. Dados biométricos de frutos e sementes de Hymenaea courbaril var. stilbocarpa (Hayne) Y. T. Lee \& Langenh e H. martiana Hayne. Biotemas, Florianópolis, v. 25, n. 3, p. 121-127, 2012.

DEMINICIS, B. B. et al. Dispersão natural de sementes: importância, classificação e sua dinâmica nas pastagens tropicais. Archivos de Zootecnia, Cordoba, v. 58, p. 35-58, 2009.

ENDRESS, M. E.; BRUYNS, P. V. A revised classification of the Apocynaceae S. L. The Botanical Review, New York, v. 66, p. 1-56, 2000.

FABRICANTE, J. R. et al. Atributos ecológicos da bioinvasora Nicotiana glauca Graham (Solanaceae) e avaliação da susceptibilidade de sua ocorrência no Brasil. Ciência Florestal, Santa Maria, v. 25, n. 4, 2015. FABRICANTE, J. R.; OLIVEIRA, M. N. A.; SIQUEIRA FILHO, J. A. Aspectos da ecologia de Calotropis procera (Apocynaceae) em uma área de Caatinga alterada pelas obras do Projeto de Integração do Rio São Francisco em Mauriti, CE. Rodriguésia, Rio de Janeiro, v. 64, n. 3, 647-654, 2013.

FERREIRA, D. F. Sisvar: Versão 5.1 (Build 72). [s. 1.]: DEX; UFLA, 2007.

FREIRE, E. S. et al. Emergência de plântulas de Bauhinia divaricata L. em diferentes posições e profundidades de semeadura. Bioscience Journal, Uberlândia, v. 30, n. 2, p. 774-782, 2014.

GIANCOTTI, P. R. F. et al. Emergência de capim-carrapicho e picão-de-flor com diferentes profundidades de semeadura em duas épocas. Bioscience Journal, Uberlândia, v. 27, n. 4, p. 619-628, 2011.

GONÇALVES, L. G. V. et al. Biometria de frutos e sementes de mangaba (Hancornia speciosa Gomes) em vegetação natural na região leste de Mato Grosso, Brasil. Revista de Ciências Agrárias, Lisboa, v. 36, n. 1, p. 31-40, 2013.

GRICE, A. C. Seed production, dispersal and germination in Cryptostegia grandiflora and Ziziphus mauritiana, two invasive shrubs in tropical woodlands of northern Australia. Australian Journal of Ecology, Carlton, v. 21, n. 3, p. 324-331, 1996.

KLACKENBERG, J. Revision of the genus Cryptostegia R. Br. (Apocynaceae, Periplocoideae). Adansonia, Paris, v. 3, n. 23, p. 205-218, 2001.

LAIME, E. M. O. et al. Emergência e crescimento inicial de plântulas de Inga ingoides (Rich.) Willd. em função de posições e profundidades de semeadura. Semina: Ciências Agrárias, Londrina, v. 31, n. 2, p. $361-372,2010$. 
MACK, R. N. et al. Biotic invasions: causes, epidemiology, global consequences and control. Ecological Applications, Washington, v. 10, n. 3, p. 689-710, 2000.

MAGUIRE, J. D. Speed of germination aid in selection and evaluation for seedling emergence and vigor. Crop Science, Madson, v. 2, n. 2, p. 176-177, 1962.

MARTINS, C. C. et al. Posição da semente na semeadura e tipo de substrato sobre a emergência e crescimento de plântulas de Schizolobium parahyba (Vell.) S.F. Blake. Ciência Florestal, Santa Maria, v. 22, n. 4, p. 845-852, 2012.

MATOS, F. S. et al. Variação biométrica de diásporos de buriti (Mauritia flexuosa L. F. - Arecaceae) em veredas em diferentes estágios de conservação. Ciência Florestal, Santa Maria, v. 24, n. 4, p. 833-842, 2014.

OLIVEIRA-BENTO, S. R. S. et al. Biometria de frutos e sementes e germinação de Calotropis procera AITON (Apocynaceae). Bioscience Journal, Uberlândia, v. 29, n. 5, p. 1194-1205, 2013.

RODRIGUES,A.J.Influênciadaprofundidadeeposiçãode semeadurana emergênciade AcaciapolyphyllaDC.

Revista Verde de Agroecologia e Desenvolvimento Sustentável, Pombal, v. 11, n. 1, p. 23-29, 2016.

SANTOS NETO, A. L. et al. Influência do peso da semente e promotores químicos na qualidade fisiológica de sementes de sambacaitá. Revista Caatinga, Mossoró, v. 22, n. 1, p. 187-192, 2009.

SILVA, S. M.; CAVALCANTE, A. M. B. Impactos ambientais e descrição morfológica comparada de duas espécies fitoinvasoras (Cryptostegia grandiflora e C. madagascariensis) no Estado do Ceará. In: CONGRESSO DE ECOLOGIA DO BRASIL, 9., São Lourenço. Anais... 2009.

SILVA, D. B. Profundidade de semeadura do trigo nos cerrados: emergência de plântulas. Agropecuária Brasileira, Brasília, v. 27, n. 9, p. 1311-1317, 1992.

SOUZA, V. C. et al. Avaliação populacional de Sesbania virgata (Cav.) Pers. (Fabaceae Lindl.), nas margens do Rio Paraíba. Revista Brasileira de Ciências Agrárias, Recife, v. 6, n. 2, p. 314-320, 2011.

STARR, F; STARR, K; LOOPE, L. Cryptostegia spp. Rubber vine Asclepiadaceae. Maui: United States Geological Survey; Biological Resources Division Haleakala Field Station, 2003.

TILLMANN, M. A. A. et al. Comparação entre diversos substratos no enraizamento de estacas de crotón (Codiaeum variegatum L.). Scientia Agricola, Piracicaba, v. 51, n. 1, p. 17-20, 1994.

TOLEDO, R. E. B.; KUVA, M.; ALVES, P. L. C. A. Fatores que afetam a germinação e a emergência de Xanthium strumarium L.: dormência, qualidade de luz e profundidade de semeadura. Planta Daninha, Viçosa, MG, v. 11, n. 1/2, p. 15-20, 1993.

TOMLEY, A. J. The biology of Australian weeds.Cryptostegia grandiflora R. Br. Plant Protection Quarterly, Frankston, v. 10, n. 26, p. 122-130, 1995.

VIEIRA, M. et. al. Biologia reprodutiva de Cryptostegia madagascariensis Bojer ex Decne. (Periplocoideae, Apocynaceae), espécie ornamental e exótica no Brasil. Bragantia, Campinas, v. 63, n. 3, p. 325-334, 2004. VIGILATO, G.; ZAMPAR, R. Suscetibilidade das zonas de recuperação de uma unidade de conservação à invasão biológica por espécies arbóreas exóticas. SaBios - Revista Saúde e Biologia, Campo Mourão, v. 6, n. 3, p. 25-37, 2011.

ZANCHETTA, D.; DINIZ, F. Estudo da contaminação biológica por Pinus spp. em três diferentes áreas na Estação Ecológica de Itirapina - SP. Revista Instituto Florestal, São Paulo, v. 18, p. 1-14, 2006.

ZENNI, R. D.; ZILLER, S. R. An overview of invasive plants in Brazil. Revista Brasileira de Botânica, São Paulo, v. 34, n. 3, p. 431-446, 2011. 